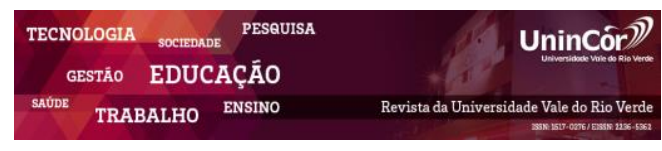

Revista da Universidade Vale do Rio Verde ISSN: 1517-0276 / EISSN: 2236-5362 v. $17 \mid$ n. 1 | Ano 2019

André Telles Campos

Universidade de Brasilia cepi@unis.edu.br

Guaracy Silva

Centro Universitário do Sul de Minas guaracy@unis.edu.br

Sheldon William Silva Universidade Federal de Lavras sheldonwilliamsilva@gmail.com

\section{UNIVERSIDADE CORPORATIVA BOMBEIRO MILITAR: UMA REALIDADE PLAUSÍVEL?}

\section{RESUMO}

Este artigo é dedicado ao estudo dos requisitos para implantação de uma instituição de ensino superior no âmbito do Corpo de Bombeiros Militar do Distrito Federal. A corporação tem histórico de afinidade com o tema da educação corporativa e ainda desenvolve programas sociais junto à comunidade do Distrito Federal. Essas características enquadram-se no conceito de universidade corporativa, que busca superar o descompasso entre o conhecimento ensinado nas escolas tradicionais e as competências exigidas pelo mercado de trabalho. Desse modo, desenvolve-se um espírito de aprendizagem contínua na organização que, alinhado com as estratégias organizacionais, transforma-se em vantagem competitiva. A metodologia empregada no estudo é a pesquisa bibliográfica combinada com um estudo de caso considerando os sete princípios fundamentais para implantação de uma universidade corporativa, propostos por Éboli (2004). A análise realizada permite concluir pela viabilidade do modelo de universidade corporativa ao se estabelecer uma visão sistêmica integradora para superar as barreiras à estruturação desse tipo de educação corporativa.

Palavras-chave: Bombeiros. Educação corporativa. Ensino. Universidade corporativa.

\section{FIREFIGHTER CORPORATE UNIVERSITY: A PLAUSIBLE REALITY?}

\begin{abstract}
This paper to the study of the requirements for the implantation of a higher education institution within the scope of the Military Fire Brigade of the Federal District. The corporation has a history of affinity with the theme of corporate education and still develops social programs with the community of the Federal District. These characteristics fit into the concept of corporate university, which seeks to overcome the mismatch between the knowledge taught in traditional schools and the skills required by the labor market. In this way, a spirit of continuous learning is developed in the organization that, in line with organizational strategies, becomes a competitive advantage. The methodology used in the study is the bibliographical research combined with a case study considering the seven fundamental principles for the implantation of a corporate university, proposed by Éboli (2004). The analysis carried out allows us to conclude on the viability of the corporate university model by establishing a systemic integrative vision to overcome the barriers to the structuring of this type of corporate education.
\end{abstract}

Keywords: Military Fire Brigade. Corporative education. Teaching. Corporate University. 


\section{INTRODUÇÃO}

O Corpo de Bombeiros Militar do Distrito Federal (CBMDF) tem como uma de suas atribuições legais a formação e a capacitação continuada de seus profissionais. Neste artigo são discutidos os ditames para a criação de uma instituição de ensino superior IES voltada às ciências do fogo e às ciências dos desastres. O termo ciências dos desastres referese à área multidisciplinar do conhecimento humano que trata de estudar os mecanismos que levam à ocorrência de desastres, sua dinâmica, bem como as metodologias de prevenção e controle de seus efeitos danosos. As ciências do fogo englobam os estudos dos mecanismos que levam à ocorrência de incêndios, a física e a química do fogo, os efeitos do fogo na fisiologia humana, bem como as metodologias de prevenção, combate, extinção e investigação de incêndios. O conceito adotado para implantação dessa IES é o de uma universidade corporativa UC. Assim, os fundamentos e os princípios de implantação de uma UC são abordados no referencial teórico.

O objetivo da pesquisa é avaliar a viabilidade de criação de uma IES no Distrito Federal sob administração do CBMDF com cursos voltados para as ciências dos desastres e as ciências do fogo. A importância dos serviços de bombeiro para a sociedade é tamanha que a instituição goza de alto grau de satisfação e confiança junto à população. No entanto, as ciências correlatas à atividade de bombeiro não se consolidaram junto ao meio acadêmico e, consequentemente, não são vistos cursos superiores de engenharia de proteção contra incêndios ou de emergências pré-hospitalares ou ainda de defesa civil, por exemplo, nas instituições de ensino tradicional. O presente estudo vem preencher esta lacuna com a discussão dos critérios de criação de cursos superiores com reconhecimento do sistema de ensino vigente para dar maior legitimidade e cientificidade às atividades de bombeiro militar. O estudo combina pesquisa bibliográfica com estudo de caso dos pontos fortes e fracos do CBMDF em relação aos sete princípios de sucesso de uma universidade corporativa, conforme proposto por Eboli (2004). A pesquisa mostra-se assim de relevante interesse para toda a sociedade e não apenas aos corpos de bombeiros militares do país.

$\mathrm{O}$ artigo pretende realçar os aspectos legais da educação superior no Brasil, desde a Constituição até a regulação normativa do Ministério da Educação no que tange ao credenciamento de IES e autorização de funcionamento de cursos. Em curso, traça-se a relação histórica entre o ensino superior e o ensino militar, chegando ao caso do CBMDF. Como arcabouço teórico, utiliza-se a temática das universidades corporativas e suas estratégias de implantação.

\section{REFERENCIAL TEÓRICO}

2.1 Aspectos legais da educação superior no Brasil e o ensino militar 
A carta magna do país estabelece a educação como um direito social de todos e dever do Estado e da família (BRASIL, 1988). A educação brasileira é dividida em dois níveis: básico (ensinos fundamental e médio) e superior. Segundo a lei de diretrizes e bases da educação LDB (BRASIL, 1996), o ensino superior tem por finalidade estimular a criação cultural e o desenvolvimento do espírito científico e do pensamento reflexivo, bem como incentivar o trabalho de pesquisa, visando o desenvolvimento da ciência, da cultura e da tecnologia e ainda o aprimoramento da educação básica.

A educação superior deve ser ministrada em instituições de ensino superior, públicas ou privadas, com variados graus de abrangência, dependendo o funcionamento da instituição de ato autorizativo do poder público nos termos da lei n. 10.861 (BRASIL, 2004). O decreto n. 5.773 (BRASIL, 2006) organiza as IES em faculdades, centros universitários e universidades, de acordo com as prerrogativas acadêmicas e a organização da instituição. As universidades gozam de autonomia didáticocientífica, administrativa e de gestão financeira e patrimonial, e obedecem ao princípio da indissociabilidade entre ensino, pesquisa e extensão (CUNHA, 2002). Tais prerrogativas podem ser estendidas aos centros universitários e faculdades que comprovarem alta qualificação para o ensino ou para a pesquisa.

O processo de credenciamento de uma IES envolve análise documental, avaliação in loco e parecer do Conselho Nacional de Educação - CNE (BRASIL, 2004). Dentre os documentos exigidos para o credenciamento destacam-se o plano de desenvolvimento institucional e a identificação dos integrantes do corpo dirigente, destacando a experiência acadêmica e administrativa de cada um. Dentro do plano de desenvolvimento institucional devem constar a missão, os objetivos e as metas da IES, o projeto pedagógico com cronograma de implantação e desenvolvimento dos cursos, a organização didático-pedagógica da instituição e os critérios de seleção e contratação, plano de carreira e regime de trabalho dos professores e ainda, estrutura adequada para atendimento às diversas práticas pedagógicas.

A implementação do ensino superior no país foi tardia, data do século XIX, e está relacionada com o ensino militar em sua origem (SANTOS; CERQUEIRA, 2009). Em 1810, com a chegada da família Real ao Brasil, criou-se a Academia Real Militar da Corte, que anos mais tarde se converteria na Universidade Federal do Rio de Janeiro. O Real Hospital Militar também serviu como embrião para a Faculdade de Medicina (ALENCAR, 2011). No entanto, as primeiras universidades com ensino integrado, e não somente a reunião de faculdades isoladas, integrando ensino, pesquisa e extensão somente viriam no século $\mathrm{XX}$, com destaque para a Universidade de São Paulo - USP em 1930 (DURHAM, 2003).

As Forças Armadas também constituíram importantes escolas superiores, consideradas referência nas áreas de engenharia como o Instituto Tecnológico da Aeronáutica ITA e o Instituto Militar de Engenharia - IME do Exército Brasileiro. O projeto pedagógico do ITA foi inicialmente concebido em 1945 de tal modo a representar um grande passo para o desenvolvimento de uma aviação genuinamente 
nacional, preconizando um plano progressivo de desenvolvimento de um instituto de pesquisas com todo seu equipamento, perfeitamente exequível (ITA, [s.d.]). O Instituto da Aeronáutica foi oficialmente estabelecido em 1950 por meio do Decreto n. 27.695, de 16 de janeiro daquele ano, com um corpo docente altamente qualificado, composto não só por professores brasileiros, mas também norteamericanos do Massachusetts Institute of Technology - MIT e da Alemanha. A história do IME está intimamente relacionada com a história da Academia Real Militar, onde se formavam não apenas Oficiais do Exército, mas, principalmente engenheiros, militares ou civis. $\mathrm{O}$ atual IME nasceu em 1959 da fusão da Escola Técnica do Exército com o Instituto Militar de Tecnologia, tornando-se um centro de excelência no ensino da engenharia (IME, [s.d.]).

$\mathrm{O}$ próprio $\mathrm{CBMDF}$ desde sua criação tem como uma de suas atribuições a profissionalização de seus integrantes por meio do ensino. A primeira escola da corporação, a Escola Regimental, foi criada em 1912 e tinha os cursos primário e médio, uma medida que "proporcionou cultura, cidadania e inclusão social" a seu efetivo (ALENCAR, 2011, p. 20). O Curso de Formação de Oficiais - CFO, ministrado pela Academia de Bombeiro Militar do CBMDF, foi reconhecido como de ensino superior em 1987 por meio de parecer do Conselho Federal de Ensino (atual CNE). Além do CFO, o CBMDF ministra outros cursos de nível superior para seus componentes: o Curso de Aperfeiçoamento de Oficiais e o Curso de Altos Estudos para Oficiais. Destaque-se ainda a atribuição definida em lei ao Corpo de
Bombeiros para ensino e pesquisa aplicada às atividades de bombeiro militar, com vistas ao desenvolvimento científico e tecnológico (BRASIL, 2010). Portanto, a criação de uma IES voltada às ciências correlatas às atividades de bombeiro militar torna-se uma extensão natural do ensino bombeiro militar e de relevante interesse.

2.2 Universidades corporativas: um caminho

Uma dificuldade enfrentada por diversos setores produtivos é o descompasso entre o conhecimento ensinado nos bancos escolares tradicionais e as competências exigidas pelo mercado de trabalho. Uma tendência de empresas bem-sucedidas foi, ao invés de esperar os currículos serem atualizados no meio acadêmico, percorrer o caminho inverso e trazer a escola para dentro da organização, entendendo a educação corporativa como um diferencial competitivo decisivo. Nesse sentido, um número crescente de empresas começou a perceber a necessidade de transferir o foco de seus esforços de treinamento e educação corporativa de eventos únicos em sala de aula para a criação de uma cultura de aprendizagem contínua (MEISTER, 1999; SILVA et al 2016).

A educação corporativa pode ser entendida como um processo no qual funcionários de todos os níveis estão envolvidos em um aprendizado contínuo e permanente para o desenvolvimento de competências individuais e organizacionais, que tem como missão favorecer o alcance das metas organizacionais. Desse modo, a educação corporativa representa, antes de qualquer coisa, uma ferramenta 
estratégica organizacional. O fundamental do conceito é que existe um objetivo maior que integra todas as ações educacionais (REIS; SILVA; EBOLI, 2010).

O termo universidade corporativa referese a um "guarda-chuva estratégico para desenvolver e educar funcionários, clientes, fornecedores e comunidades, a fim de cumprir as estratégias empresariais da organização" (MEISTER, 1999, p. 29). Dentro dessa visão, a universidade corporativa estende seus serviços ao público externo, cobrindo toda sua cadeia de valor e também estabelece parcerias com instituições de ensino tradicional, o que culmina com o aproveitamento de créditos e outorga de diplomas reconhecidos

(SANTOS;

ZAMBALDE; BRITO, 2006). Isso pode ser comprovado pelo fato de que presidentes de importantes empresas investem uma parcela significativa de seu tempo na tarefa de criar parcerias educacionais com o mundo acadêmico e declarar publicamente a importância do aprendizado como vantagem competitiva para a organização (MEISTER, 1999).

Uma vez que o objetivo principal da educação corporativa é o desenvolvimento de competências críticas para a viabilização das estratégias organizacionais. Organizações "interessadas em projetos de educação corporativa realizam esforços intensos para mapear suas competências críticas e investem em gestão do conhecimento". Nesse sentido, destaque-se os projetos de educação para setores de atividades e não apenas para uma organização. Nesses casos o "objetivo é formar profissionais com o perfil de competências exigido pelo setor e também promover a gestão do conhecimento setorial mediante a realização de pesquisas e prestação de serviços" (EBOLI, 2004, p. 69).

Um aspecto bastante ressaltado nos projetos bem-sucedidos de educação corporativa é o uso de tecnologias "para criar um ambiente organizacional propício à aprendizagem ativa, contínua e compartilhada" (EBOLI, 2004, p. 146). Cabe ressaltar que os ambientes virtuais de aprendizagem requerem do aluno uma postura proativa e de autoconhecimento, exigindo, assim, um esforço de adaptação a essa nova cultura. A parceria deve ser benéfica para todas as partes envolvidas, conciliando os objetivos do aluno, da corporação e da instituição de ensino.

Uma reflexão que cabe ser feita diz respeito ao seguinte questionamento: há dicotomia entre universidade corporativa $\mathrm{e}$ pensamento reflexivo? Para responder a isso é pertinente em primeiro lugar esclarecer o uso do termo "universidade" para rotular o sistema integrado e estratégico de educação corporativa. Eboli (2004, p. 198) esclarece que "de modo geral, os mais tradicionais torcem o nariz para o emprego indevido do termo, [...] que a expressão 'universidade corporativa' é uma metáfora e foi cunhada nos Estados Unidos".

Otranto (2007, p. 1) expõe seus fundamentos para recusar convite de trabalho para esse "tipo de educação superior que vem se multiplicando no Brasil e no mundo". A autora critica a proposta de interferência direta das empresas nas instituições educacionais formais para que estas atendam ao mercado com um ensino considerado descartável. Ela sintetiza explicando que "a educação permanente na universidade acadêmica é vista como uma 
aprendizagem para a vida toda, enquanto que a da universidade corporativa atende a uma determinada necessidade, em espaço e tempo limitados" (OTRANTO, 2007, p. 3). Otranto (2007) constata ainda que as universidades corporativas a que ela teve acesso ainda estariam muito distantes da proposta de sua principal teórica, J. Meister, visto que o escopo dos cursos foi reduzido aos funcionários executivos e não leva em consideração as relações sociais mediadoras existentes entre a empresa e o mundo do trabalho.

Meister (1999), em sua obra, explica que as universidades corporativas nos Estados Unidos estariam pressionando o ensino superior tradicional a mudar seu modelo educacional para os trabalhadores adultos, com uma visão cada vez mais voltada para o mercado. Mas, será que isso é incompatível com o que preconiza a legislação educacional brasileira? Vejamos o que diz a LDB em seu art. $2^{0}$ quanto às finalidades da educação: "A educação [...] tem por finalidade o pleno desenvolvimento do educando, seu preparo para o exercício da cidadania e sua qualificação para o trabalho" (BRASIL, 1996, grifo nosso). Ou seja, as instituições acadêmicas tradicionais não devem se subordinar ao mercado, mas também não podem se distanciar dele a tal ponto de comprometer sua finalidade de formação para o trabalho.

Apesar da necessária e profícua colaboração entre academia e empresa, é preciso preservar a essência do papel de cada instituição. "As UCs têm como objetivo desenvolver nos profissionais as competências críticas para a viabilização das estratégias empresariais" (EBOLI, 2004, p. 204). Já as universidades públicas têm um compromisso primeiro com a sociedade que as mantém e esse compromisso, segundo Otranto (2007, p. 12), “envolve a identificação e análise de problemas concretos a serem estudados, comprometidos e vinculados à realidade local, a fim de que possa nela atuar, operar e trabalhar pela transformação social".

\section{METODOLOGIA}

A pesquisa possui um caráter descritivo ao considerar como principal objetivo avaliar a viabilidade de criação de uma IES no Distrito Federal sob administração do CBMDF com cursos voltados para as ciências dos desastres e as ciências do fogo (GIL, 2002; VERGARA, 2003). Quanto aos meios adotados para a coleta de dados, a pesquisa é documental, pois utiliza vários materiais como livros, periódicos, jornais, documentos, portarias, leis e outros recursos de comunicação. Ademais, considera-se o fato de sua abordagem qualitativa, tendo em vista que a mesma pretende obter dados descritivos mediante contato direto e interativo do pesquisador com a situação objeto do estudo e interpretar esses dados (GIL, 2002; de SOUZA MINAYO, 2011)

Pode-se ainda considerar essa pesquisa como um estudo de caso. De acordo com Gil (2002, p.54) o estudo de caso consiste no "estudo profundo e exaustivo de um ou de poucos objetos, de maneira a permitir o seu conhecimento amplo e detalhado". O foco do estudo de caso considera os pontos fortes e fracos do CBMDF visando a implantação de uma universidade Corporativa. Tendo em vista que a 
pesquisadora Eboli (2004) é uma referência no Brasil em pesquisa acadêmica sobre educação corporativa e na disseminação do conceito em inúmeras organizações de destaque no cenário empresarial brasileiro (FISCHER e AMORIM,
2010), delimitou-se, como critério de análise os sete princípios de sucesso de uma universidade corporativa, propostos pela autora, conforme demonstrado no quadro 1 :

Quadro 1 - Sete princípios e práticas de sucesso da educação corporativa

\begin{tabular}{|c|c|}
\hline Princípios & Práticas \\
\hline Competitividade & $\begin{array}{l}\text { Valorizar a educação como forma de desenvolver o capital intelectual dos colabora- } \\
\text { dores, transformando-os efetivamente em fator de diferenciação da empresa }\end{array}$ \\
\hline Perpetuidade & $\begin{array}{c}\text { Entender a educação também como processo de transmissão de herança cultural, a } \\
\text { fim de perpetuar a existência da empresa }\end{array}$ \\
\hline Conectividade & $\begin{array}{l}\text { Privilegiar a construção social do conhecimento, estabelecendo conexões com o } \\
\text { público interno e externo }\end{array}$ \\
\hline Disponibilidade & $\begin{array}{c}\text { Ofertar recursos educacionais que estimulem a aprendizagem a qualquer hora e em } \\
\text { qualquer lugar }\end{array}$ \\
\hline Cidadania & $\begin{array}{l}\text { Estimular o exercício da cidadania, formando sujeitos capazes de refletir } \\
\text { criticamente sobre a realidade organizacional e de modifica-la com atuação ética e } \\
\text { socialmente responsável }\end{array}$ \\
\hline Parceria & $\begin{array}{l}\text { Estabelecer parcerias internas com a alta cúpula da organização e parcerias externas } \\
\text { com IES }\end{array}$ \\
\hline Sustentabilidade & Agregar valor à organização e buscar a auto sustentabilidade financeira \\
\hline
\end{tabular}

Fonte: Éboli, 2004.

\section{ANÁLISE DOS RESULTADOS}

Cabe neste momento discutir a aplicação dos sete princípios propostos por Eboli (2004) e a disponibilidade de recursos para se desenvolver uma universidade corporativa no âmbito do CBMDF.

$\mathrm{O}$ primeiro princípio diz respeito à competitividade, isto é, a disposição da organização para transformar o capital intelectual em fator de diferenciação da empresa. Neste ponto, vale destacar o que diz o plano estratégico do CBMDF. Inicialmente destacam-se os valores da Corporação, dentre eles a responsabilidade social: "O CBMDF tem o compromisso com o desenvolvimento social, trabalhando em conjunto com os seus integrantes, suas famílias, a comunidade local e a sociedade em geral para melhorar sua qualidade de vida" (CBMDF, 2015). Nesses valores estão expressos os ideais da UC no sentido de atender toda a cadeia de valor, e não apenas os altos executivos, para atingir os objetivos organizacionais. Adicionalmente, tem-se os objetivos permanentes da instituição, que são seis. Sendo um deles "qualificar e valorizar profissionalmente seus integrantes" (CBMDF, 2015). Do documento norteador das ações da corporação vê-se a clara disposição para se efetivar o princípio da competitividade.

O princípio da perpetuidade está claramente expresso também no plano estratégico da corporação, especificamente no valor tradição: "O CBMDF busca conservar, 
respeitar e transmitir as boas práticas e valores forjados pelas gerações de bombeiros militares" (CBMDF, 2015). Com isso o CBMDF busca se valer da educação para forjar a cultura organizacional e transmitir as boas práticas.

O princípio da conectividade consiste em ampliar a qualidade da interação com o público interno e externo. Para isso a corporação ainda precisa implantar um modelo de gestão do conhecimento que estimule o compartilhamento de saberes e se integre ao sistema de educação corporativa. Esse talvez seja o ponto mais incipiente de uma iniciativa para se desenvolver um projeto de UC no CBMDF. Apesar disso, há estruturas organizacionais que favorecem a implantação de tais sistemas integrados, tais como a diretoria de pesquisa e a diretoria de ensino trabalhando conjuntamente num departamento único.

Outro ponto que ainda apresenta necessidade de melhorias para a implementação de uma UC no CBMDF é a disponibilidade de recursos para implantar projetos virtuais de educação. No entanto, já existem iniciativas em andamento nesse sentido. $O$ curso de altos estudos para Praças está sendo realizado com recursos de aprendizagem mediada pela tecnologia. O estabelecimento de ensino contratou consultores e implementou a iniciativa pioneira com bons resultados até o momento. Outro ponto facilitador da inserção do princípio da disponibilidade é a existência de uma diretoria de tecnologia da informação com profissionais do quadro permanente da corporação especializados na área. A cultura do processo eletrônico está sendo disseminada por meio do uso do sistema eletrônico de informações - SEI para tramitação de todos os documentos na instituição. Isso contribui para facilitar a adaptação às novas tecnologias por parte dos colaboradores, principalmente os mais antigos.

A construção social do conhecimento organizacional por meio da sinergia entre programas sociais e educacionais é um caminho bastante real para o CBMDF. A corporação é vocacionada, por conta da peculiaridade de suas atividades, à maior proximidade e interação com a comunidade. O CBMDF possui uma escola de educação básica, pertencente ao sistema de ensino público do DF, sob sua administração, o colégio militar d. Pedro II. A escola atende à comunidade em geral e não somente aos dependentes de militares. A comunidade também é atendida por meio de programas sociais, tais como o bombeiro mirim, criado pela lei n. 2.449, de 24 de setembro de 1999, e regulamentado pelo decreto n. 21.104, de 31 de março de 2000; e o bombeiro amigo, desenvolvido para o público da terceira idade pela lei n. 2.811 , de 30 de outubro de 2001. Portanto, o princípio da cidadania tem plenas condições de se efetivar na UC.

O princípio da parceria tem dois vieses: as parcerias internas e as parcerias externas. A parceria interna com a alta cúpula da organização mostra-se fundamental para se estabelecer o compromisso com o cultivo e o gerenciamento do capital intelectual. Esse aspecto tem ganhado relevo na alta administração da corporação, mas ainda precisa ser reforçado e ampliado. As parcerias externas com IES já são uma realidade no CBMDF. Como já citado, há o caso da parceria com a Universidade Católica de Brasília 
no projeto "bombeiros do futuro". Mas, não se restringem a isso; os cursos de carreira regularmente fazem uso de professores civis para algumas disciplinas por meio da contratação com alguma IES, que já foi a Universidade de Brasília, a Famatec e mais recentemente a Funadem. Assim, a melhor estratégia neste ponto é reafirmar as parcerias, visto que não há mestres e doutores em número suficiente na corporação para dar sustentação ao implemento imediato de uma UC com reconhecimento junto ao MEC.

O princípio de sustentabilidade, relacionado com agregação de valor ao negócio, está imbricado com um sistema métrico para avaliar os resultados do capital intangível na organização. Eboli (2004, p. 219) destaca que "um dos maiores desafios enfrentados hoje pelas empresas é criar indicadores eficazes de mensuração dos resultados obtidos com os investimentos em treinamento". Essa realidade não é diferente no CBMDF. Os indicadores institucionais de gestão estão em fase inicial de implantação e pouco ou nada dizem respeito ao capital intelectual. De tal modo que esse ponto deva ser atacado para que se dimensione o impacto das ações educacionais nas estratégias organizacionais.

Indo além dos sete princípios e abordando também as questões técnicas da legislação de ensino, resta destacar alguns pontos. Em termos legais, cabe ao CBMDF a formação e a capacitação continuada de seus quadros sob a égide do ensino militar. Em termos de estrutura física, o CBMDF ainda apresenta deficiências em sua biblioteca e na infraestrutura de laboratórios para um curso de engenharia de proteção contra incêndios, por exemplo. No entanto, possui um centro de treinamento operacional e laboratórios de apoio pericial, bem como expertise de formação de nível superior em sua Academia de Bombeiro Militar. Acrescentem-se os cursos de ascensão na carreira dos Oficiais, realizados em nível de pósgraduação, e a recente mudança na legislação, em 2009, que alçou a exigência em concurso de ingresso de ensino médio para ensino superior, tanto para Praças quanto para Oficiais da corporação. Donde se extrai que houve nos últimos anos um significativo acréscimo na qualificação de pessoal no que tange a titulação acadêmica

\section{CONSIDERAÇÕES FINAIS}

O CBMDF tem vocação para implantar um sistema de ensino baseado no conceito de universidade corporativa. A corporação possui um histórico ligado ao ensino para seus colaboradores e ainda investe em ações socioeducacionais para a comunidade em geral, alinhando isso em seu planejamento estratégico. A estrutura organizacional também é um fator facilitador à implementação da UC, pois já dispõe de um departamento de ensino, pesquisa, ciência e tecnologia cuja chefia faz parte da alta administração da organização. Além disso, essa estrutura integra ensino e pesquisa, como preconiza a legislação do MEC acerca das universidades. Outro ponto favorável ao início de uma UC é a tecnologia da informação em grande medida disseminada pelos processos digitais do CBMDF via SEI e com suporte de uma diretoria de tecnologia da informação, proporcionando 
uma porta de entrada às plataformas de educação a distância. Outro elemento positivo é a experiência em estabelecer parcerias com IES para fornecimento de professores para os cursos existentes na corporação. No entanto, esses fatores facilitadores à implantação de uma UC no CBMDF ainda carecem de uma visão sistêmica integradora.

Existem fatores desafiadores à implantação da UC no CBMDF. A instituição ainda não dispõe de um modelo de gestão do conhecimento que se integre ao sistema de educação corporativa. Indicadores nesta área sequer foram estabelecidos. Outro dificultador é a legislação a que o sistema de ensino do CBMDF deve se submeter, visto que ainda não há uma lei de ensino militar para a organização. Desse modo, a corporação deve adotar cuidadosamente a regulamentação do MEC onde se aplica e, em analogia, a lei de ensino do Exército.

Desse modo, é possível concluir que a criação de uma universidade bombeiro militar nos moldes do que é exigido pelo MEC ainda é uma realidade distante para o CBMDF. No entanto, toda longa caminhada exige um primeiro passo. E esse primeiro passo representa a estruturação do sistema de ensino bombeiro militar com base no conceito de universidade corporativa.

Este artigo não tem o condão de esgotar o tema, muito pelo contrário, ele abre caminhos para novos estudos. A etapa inicial de implantação da UC exige o mapeamento de competências para definição das necessidades de educação corporativa. Outro campo que se abre a partir desta pesquisa é o estabelecimento de cursos e a proposição de currículos contemplando os três de Cs de Meister (1999). Essa proposta pedagógica da UC deve contemplar toda a cadeia de valor e levar em conta a questão da certificação aos concludentes de acordo com os ditames legais do MEC, seja por meio de parcerias com outras IES ou pelo caminho da certificação própria. A autossustentabilidade financeira da UC e os indicadores de agregação de valor ao negócio são ainda outros campos a serem explorados em pesquisas posteriores.

\section{REFERÊNCIAS}

ALENCAR, L. C. de A. (2011). Equivalência de cursos superiores militares e civis: Caminhos para o Corpo de Bombeiros Militar do Distrito Federal. Monografia. CBMDF - Brasília.

BRASIL. (1988). Constituição da República Federativa do Brasil. Brasília.

BRASIL. (2006). Decreto n. 5.773, de 9 de maio de 2006. Brasília.

BRASIL. (2010). Decreto n. 7.163, de 29 de abril de 2010. Brasília.

BRASIL. (1996). Lei n. 9.394, de 20 de dezembro de 1996. Brasília.

BRASIL. (2004). Lei n. 10.861, de 14 de abril de 2004. Brasília.

CASALETTI, B. B. (2013). Educação corporativa: um tema da contemporaneidade. Gestão \& Aprendizagem, 2(1).

CBMDF. (2016). Plano estratégico 2013-2016: versão 3.0. Acesso em 11 de abril de 2016, disponível em https://www.cbm.df.gov.br/institucional/planeja mento-estrat $\% \mathrm{C} 3 \%$ A9gico?task $=$ do cument. viewdoc\&id=2955 
CUNHA, M. C. A. (2002). A dinâmica e os fatores condicionantes da criação de cursos da educação superior no Estado da Bahia. Tese de Doutorado. Universidade Federal da Bahia.

DE SOUZA MINAYO, M. C. (2011). Pesquisa social: teoria, método e criatividade. Editora Vozes Limitada.

DURHAM, E. R. (2003). O ensino superior no Brasil: público e privado. NUPES-USP.

ÉBOLI, M. P. (2004). Educação corporativa no Brasil: mitos e verdades. São Paulo: Editora Gente.

FISCHER, A. L., \& AMORIM, W. A. (2010). Gestão do Conhecimento e Educação Corporativa: integração, complementaridade e sobreposições. M. Eboli, AL Fischer, \& FC Moraes, Educação Corporativa: Fundamentos, evolução e implantação de projetos, 3-18.

GIL, A. C. (2002). Como elaborar projetos de pesquisa. São Paulo, 5, 61.

IME. História do IME. Acesso em 12 de fevereiro de 2017, disponível em http://www.ime.eb.br/ime/historia.html

ITA. Criação do ITA. Acesso em 12 de fevereiro de 2017, disponível em http://www.prograd.ita.br/criacao.php

MEISTER, J. C. (1999). Educação corporativa: a gestão do capital intelectual através das universidades corporativas.

OTRANTO, C. R. (2007). Universidades corporativas: o que são e para que servem.

REIS, G. G., DA SILVA, L. M. T., \& EBOLI, M. P. (2010). A prática reflexiva e suas contribuições para a educação corporativa. REGE Revista de Gestão, 17(4), 403-419.

SANTOS, A. P. D., \& CERQUEIRA, E. A. D. (2011). Ensino Superior: trajetória histórica e políticas recentes.

SANTOS, A. C., ZAMBALDE, A. L., \& de BRITO, M. J. (2006, January). UNIVERSIDADE CORPORATIVA: uma estratégia de educação corporativa da Polícia Militar. In Anais do Workshop de Informática na Escola (Vol. 1, No. 1).
SILVA, S. W., SARSUR, A. M., de VASCONCELOS, M. C. R. L., \& da FONSECA, L. R. (2016). E-Learning e Educação Corporativa: a análise de um programa a partir do princípio da conectividade. Revista ESPACIOS| Vol. 37 (N² 26) Año 2016.

VERGARA, S. C. (2003). Gestão de pessoas. São Paulo: Atlas, 2003. _. Projetos e relatórios de pesquisa em administração, 7.

André Telles Campos
Doutor em Física pela Universidade de Brasília
(2013), é bacharel e licenciado em Física (UnB,
2005). Engenheiro Mecânico (UnB, 2015), graduado
em Engenharia de Incêndio pela Academia de
Bombeiro Militar (1998) com especialização em
Engenharia de Segurança do Trabalho pela UnB
(2004). Tenente-Coronel do Corpo de Bombeiros
Militar do Distrito Federal, realiza pesquisas nas
áreas de Física e Engenharia, com ênfase em
dinâmica de incêndios. Gestor da área de ensino do
CBMDF, atualmente exerce a função de coordenador
de articulação institucional da Subsecretaria de
Ensino e Valorização Profissional da SSPDF.

Guaracy Silva
É doutor em Educação pela Universidade Metodista
de Piracicaba - UNIMEP (2015) tendo realizado
estágio sanduíche na Universidade de Lisboa (2013).
Possui graduação em Administração de Empresas
pela Sociedade Riopretense de Ensino e Educação
(1996) e mestrado em Administração pelo Centro
Universitário de Franca - UNIFACEF (2005).
Atualmente é superintendente corporativo do Grupo
Educacional UNIS e professor dos programas de
graduação e pós-graduação da mesma instituição.
Pesquisa temas relacionados a gestão de instituições
de ensino superior, tendências na oferta do ensino
superior, políticas públicas para o ensino superior em
especial o PNE.

Sheldon William Silva
Doutorando em Administração pela Universidade
Federal de Lavras. Mestre em Administração pela
Fundação Pedro Leopoldo, Especialista em Gestão
Empresarial e graduado em Administração com
Habilitação em Comércio Exterior pela Universidade
do Estado de Minas Gerais. Coordenador do Núcleo
de Graduação - Faculdades do Grupo Unis.
Pesquisador do Centro de Empreendedorismo,
Pesquisa e Inovação (CEPI-UNIS.

